Arq. Bras. Med. Vet. Zootec., v.67, n.1, p.37-40, 2015

\title{
Intussuscepção uterina em uma cadela Yorkshire Terrier
}

[Uterine intussusception in a Yorkshire terrier bitch]

\author{
S.T.L. Pinto Filho ${ }^{1}$, D.S. Carus $^{2}$, F. Dalmolin ${ }^{1}$, B.L. Anjos ${ }^{3}$, T. Segatto ${ }^{3}$, A. Krabbe ${ }^{3}$, \\ M.T. Oliveira ${ }^{1}$, N.L. Pippi ${ }^{1}$, M.V. Brun ${ }^{1}$ * \\ ${ }^{1}$ Aluno de pós-graduação - Universidade Federal de Santa Maria -UFSM- Santa Maria, RS \\ ${ }^{2}$ Médica veterinária autônoma \\ ${ }^{3}$ Universidade Federal do Pampa - Unipampa - Uruguaiana, RS
}

\begin{abstract}
RESUMO
A intussuscepção uterina é condição rara em pequenos animais. No presente relato descreve-se um caso de intussuscepção uterina em um canino, fêmea Yorkshire Terrier no pós-parto imediato, diagnosticada por meio de laparotomia exploratória e pela avaliação anatomopatológica. Realizou-se a ovariossalpingohisterectomia (OSH) como tratamento definitivo para a alteração. Conclui-se, portanto, que a intussuscepção uterina pode ocorrer em cadelas, de forma espontânea no pós-parto imediato.
\end{abstract}

Palavras-chave: cão, cirurgia, inversão uterina, parto

\begin{abstract}
Uterine intussusception has rarely been described in small animals. In this report we describe a case of uterine intussusception in a female Yorkshire terrier immediately postpartum, diagnosed by exploratory laparotomy and anatomopathologic evaluation. Ovariosalpingohisterectomy (OSH) was performed as definitive treatment. It is concluded that the intussusception of the uterus may occur spontaneously in dogs immediately postpartum.
\end{abstract}

Keywords: dog, surgery, uterine inversion, parturition

\section{INTRODUÇÃO}

O útero é o órgão reprodutivo muscular que serve como local de inserção para óvulos fertilizados e que proporciona fonte de nutrição fetal, sendo formado pela cérvix, um corpo e dois cornos (Wykes e Olson, 1996). O corpo uterino tem cerca de $1,5 \mathrm{~cm}$ de comprimento e $1 \mathrm{~cm}$ de largura nas cadelas, enquanto nas gatas pode ter $2 \mathrm{~cm}$ de comprimento. Está localizado parcialmente na cavidade pélvica, mas em fêmeas pluríparas pode se posicionar totalmente dentro da cavidade abdominal. O corpo uterino situa-se entre o cólon descendente e a bexiga. Uma projeção interna musculomembranosa, não visível externamente, estende-se $1 \mathrm{~cm}$ para dentro deste, dividindo o lúmen uterino longitudinalmente. Nas cadelas, a cérvix possui cerca de $1 \mathrm{~cm}$ de comprimento (Stone, 2007). O tubérculo cervical situa-se na extremidade cranial da prega média dorsal e está separado por uma prega transversal evidente (Wilson, 2003). $\mathrm{O}$ orifício interno da cérvix está voltado quase que dorsalmente, e o orifício externo está direcionado ventralmente, na direção do assoalho vaginal (Wilson, 2003; Stone, 2007).

As anomalias congênitas uterinas em caninos ou felinos são raras, podendo ocorrer atresia, aplasia segmentar, corpo uterino septado, hipoplasia, fusão cornual, cérvix dupla e agenesia de corno uterino (útero unicórnio), sendo esta a mais comum (Pinto Filho et al., 2001; Stone, 2007). Já entre as anomalias adquiridas, encontram-se a hiperplasia endometrial cística/piometra, a hidrometra, a subinvolução dos sítios

Recebido em 28 de fevereiro de 2013

Aceito em 16 de dezembro de 2013

*Autor para correspondência (corresponding author)

E-mail: mauriciovelosobrun@hotmail.com 
placentários, a metrite, a torção, o prolapso, a ruptura, casos de neoplasias e intussuscepção, sendo esta última a mais rara (Stone, 2007). Yang et al. (2004) afirmaram que a intussuscepção do corno uterino é complicação frequente em partos distócios de equinos e bovinos, mas raramente vista em outras espécies. Já Palmieri et al. (2011) afirmaram que a intussuscepção de tuba uterina, invaginando-se para dentro do corno uterino, pode ocorrer em ovelhas, embora seja raramente reportada e provavelmente decorra de incoordenação no peristaltismo ao longo da tuba.

De acordo com a literatura consultada, a intussuscepção uterina foi descrita uma única vez em uma cadela da raça Chow-Chow que apresentava corrimento vaginal sanguinolento por quatro semanas. Após realização de laparotomia exploratória e ovariossalpingohisterectomia (OSH), foi verificado encurtamento do corno uterino esquerdo por invaginação deste, próximo a sua junção com a tuba uterina. A OSH foi realizada com sucesso (Gorham e Spink, 1975). A diferença para o prolapso uterino é que este se caracteriza pela eversão e protrusão de uma porção do útero através da cévix para a vagina durante ou próximo ao momento do parto (Hedlund, 2007).

Em humanos, foi descrito um caso de inversão uterina não puerperal associada a um teratoma uterino em uma adolescente de 15 anos de idade que apresentava sangramento vaginal, dor abdominal e anemia sintomática. Segundo os autores, essa alteração é rara, de difícil diagnóstico pré-operatório e geralmente é associada a doenças malignas em mulheres jovens (Lobo et al., 2007).

O objetivo do presente trabalho foi relatar um caso de intussuscepção uterina em um canino, fêmea, Yorkshire Terrier, no pós-parto imediato.

\section{CASUÍSTICA}

Foi encaminhado para atendimento veterinário um canino, fêmea, Yorkshire Terrier, com quatro anos de idade e $3 \mathrm{~kg}$ para acompanhamento de parto. A cadela estava gestando há 65 dias e apresentava sinais de parto iminente, procurando fazer ninho, apresentando tremores musculares e dispneia. Após alguns minutos, em sequência, houve a expulsão de três filhotes normalmente, sendo que o segundo veio a óbito logo após o nascimento. Procedeu-se então ao exame obstétrico e à palpação abdominal da cadela, procurando-se verificar quanto à ausência de fetos no interior do útero, a fim de confirmar a ultrassonografia realizada aos 35 dias de gestação, na qual foi verificada a presença de três filhotes. Decorridos 30 minutos da expulsão do último filhote, o animal apresentou contrações uterinas e abdominais, sendo estas fracas e curtas. Após outra palpação abdominal, verificou-se a presença de um aumento de volume uterino, aparentemente no corno direito, compatível com a presença de outro feto. Foi realizado toque vaginal, porém o aumento de volume não foi alcançado ao toque. Nesse momento foi administrada $1 \mathrm{UI} / \mathrm{kg}$ de ocitocina, $\mathrm{SC}$, e o animal seguia com as contrações improdutivas. Sessenta minutos depois, optou-se pela realização da laparotomia exploratória na busca da resolução da condição estabelecida.

O animal foi sedado com cloridrato de xilazina $(1 \mathrm{mg} / \mathrm{kg})$ e cloridrato de tramadol $(2 \mathrm{mg} / \mathrm{kg})$, ambos IM. A seguir, procedeu-se à tricotomia ampla do abdome, cateterização venosa para fluidoterapia com Ringer lactato e indução com propofol $(10 \mathrm{mg} / \mathrm{kg}, \quad$ IV). A manutenção anestésica foi realizada com vaporização de isoflurano em oxigênio a $100 \%$. Após antissepsia com álcool-iodo-álcool, realizou-se incisão mediana ventral retroumbilical, com bisturi, completando-a com tesoura Metzenbaum. Verificou-se que o segmento cranial do corno uterino direito invaginava-se (intussuscepto) no lúmen do segmento localizado logo a seguir no sentido caudal (intussuscipiente), e o ovário ipsilateral quase fazia parte do segmento intussuscipiente (Fig. 1). Em seguida, foi feita tentativa de desfazer a invaginação, porém sem sucesso, optando-se então pela OSH pelo método com três pinças (Stone, 2007). A ligadura dos pedículos ovarianos e do corpo uterino foi realizada com categute cromado 2-0. Procedeuse à sutura muscular com náilon 2-0 em padrão Sultan e à do tecido subcutâneo com categute 2-0 em padrão zigue-zague. A sutura cutânea foi realizada com náilon 3-0 em padrão interrompido simples.

No período pós-operatório foram administrados meloxican $(0,2 \mathrm{mg} / \mathrm{kg}$, SC, SID, por três dias), cloridrato de tramadol $(2 \mathrm{mg} / \mathrm{kg}, \mathrm{SC}, \mathrm{BID}$, durante três dias) e cefalexina $(30 \mathrm{mg} / \mathrm{kg}, \mathrm{VO}$, 


\section{Intussuscepção uterina...}

TID, por sete dias). Foi obtida total recuperação do animal após o procedimento. Segundo contato telefônico com a proprietária, após 10 meses o animal estava hígido.

O útero e os ovários foram encaminhados à avaliação anatomopatológica para análise macro e microscópica. Na macroscopia observou-se invaginação do corno uterino direito e área focalmente extensa de hemorragia de estruturas anexas (Fig. 2). Na microscopia observou-se necrose hemorrágica, caracterizada pela congestão e pela hemorragia focalmente extensas em segmentos invaginados com áreas leves de necrose em células das camadas mucosa e muscular. Observou-se ainda pequeno foco de infiltrado inflamatório linfoplasmocitário. O diagnóstico, portanto, após estudo anatomopatológico, confirmou a intussuscepção de corno uterino com necrose hemorrágica, conforme já havia sido observado na OSH.

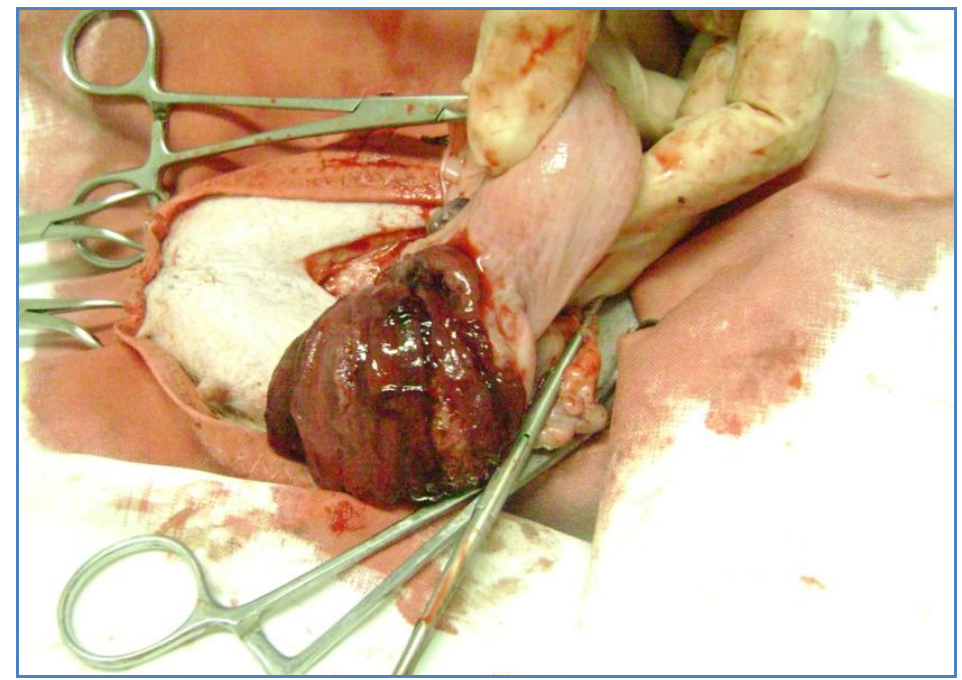

Figura 1. Cão. Yorkshire Terrier de quatro anos, com intussuscepção uterina. Observar que o segmento cranial do corno uterino direito invagina-se no caudal, quase envolvendo também o ovário ipsilateral (junto à pinça hemostática em primeiro plano) durante a OSH.

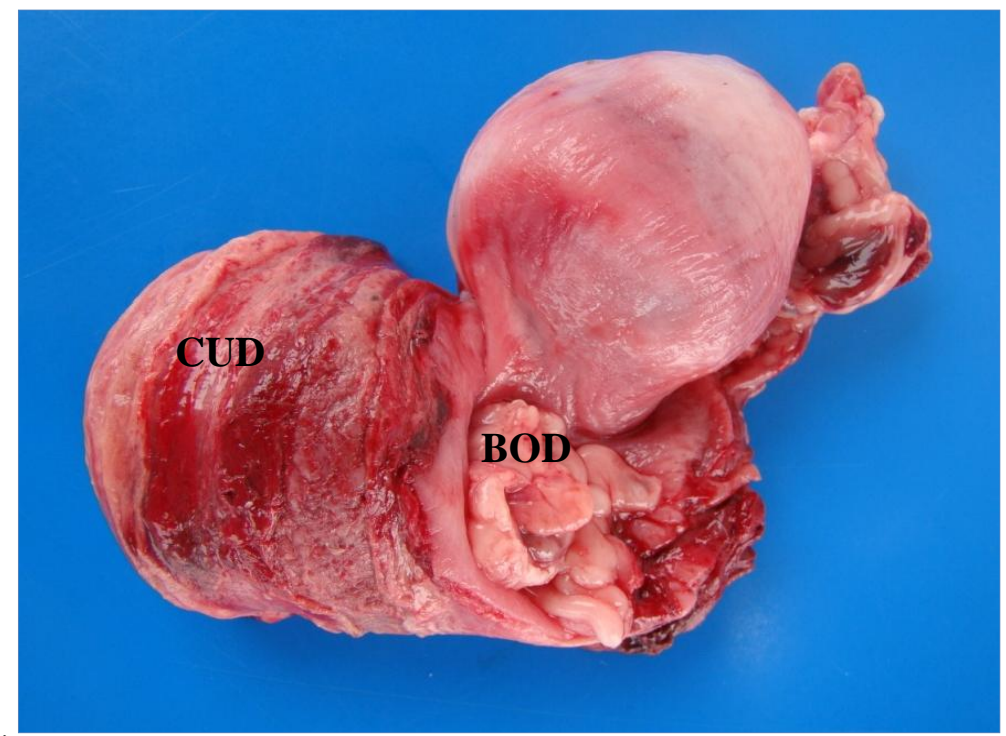

Figura 2. Cão. Útero de uma Yorkshire Terrier, de quatro anos, com intussuscepção uterina. Observa-se invaginação do corno uterino direito (CUD) com área focalmente extensa de hemorragia e bolsa ovariana direita (BOD) insinuada no segmento intussuscepto. 


\section{DISCUSSÃO}

A literatura veterinária quase não se refere a casos de intussuscepção uterina, sendo essa condição considerada bastante rara em pequenos animais (Stone, 2007). Conforme consulta na literatura, verificou-se a indisponibilidade de referências atuais e artigos científicos sobre o assunto, visto que foi encontrada apenas uma ocorrência similar da década de 1970 (Gorham e Spink, 1975).

O caso aqui reportado envolveu uma cadela que foi encaminhada para atendimento rotineiro associado ao acompanhamento de um parto aparentemente normal, sendo a doença um achado incidental. No relato descrito por Gorham e Spink (1975), a fêmea acometida era da raça Chow-Chow, diferindo do presente trabalho, o qual envolveu a doença numa cadela Yorkshire Terrier. No caso descrito em 1975, a fêmea foi levada ao veterinário, pois estava apresentando descarga hemorrágica vaginal que, num primeiro momento, pensou-se tratar-se de pró-estro precoce, já que a paciente na época apresentava cinco meses de idade. No presente caso, a cadela foi encaminhada por apresentar sinais iminentes de parto, após 65 dias de gestação. Portanto, aparentemente essa doença pode acometer fêmeas em diferentes momentos do ciclo estral.

Em ambos os relatos, os animais foram tratados por meio da $\mathrm{OSH}$, sem realização de exames de imagem. No presente caso, a ecografia não foi realizada devido à indisponibilidade do equipamento na cidade em que a paciente residia, e no relato de Gorham e Spink (1975) o diagnóstico por imagem pode não ter sido realizado por dificuldade de acesso a essa tecnologia na época, já que ocorreu há 38 anos. Ainda assim, em ambas as situações, o exame clínico foi essencial para a tomada de decisão cirúrgica, essencial para a resolução da doença em questão.

Para a escolha e a concretização do correto tratamento, é importante diferenciar a intussuscepção uterina do prolapso. A primeira condição se caracteriza pela eversão e protrusão de uma porção do útero através da cévix para a vagina durante ou próximo ao momento do parto (Hedlund, 2007). No caso aqui relatado, não houve nenhum tipo de exposição uterina através da vagina e da vulva. Além disso, a histologia permitiu confirmar o diagnóstico obtido após a celiotomia, não restando dúvidas quanto à doença em questão.

\section{CONCLUSÃO}

Conclui-se, portanto, que a intussuscepção uterina pode ocorrer em cadelas, de forma espontânea, no pós-parto imediato.

\section{REFERÊNCIAS}

GORHAM, M.F.; SPINK, R.R. Uterine intussusception in a chow chow. Mod. Vet. Pract., v.56, p.35, 1975.

HEDLUND, C.S. Surgery of the reproductive and genital systems. In: FOSSUM, T.W. Small animal surgery. 3.ed. St. Louis: Mosby Elsevier, 2007. Chap. 26, p.702-774.

LOBO, V.G.; BURCH, W.; KHANNA, P.C. Nonpuerperal uterine inversion associated with an immature teratoma of the uterus in an adolescent. Gynecol. Obstet., v.110, p.491-493, 2007.

PALMIERI, C.; SCHIAVI, E.; DELLA SALDA, L. Congenital and acquired pathology of ovary and tubular genital organs in ewes: a review. Theriogenology, v.75, p.393-410, 2011.

PINTO FILHO, S.T.L.; CUNHA, O.; RAISER, A.G. et al. Agenesia unilateral de corno uterino em cadela relato de caso. Arq. Cienc. Vet. Zool. UNIPAR, v.4, p.77-79, 2001

STONE, E.A. Ovário e útero. In: SLATTER, D. Manual de cirurgia de pequenos animais. 3.ed. São Paulo: Manole, 2007. Cap. 98, p.1487-1502.

WILSON, M.S. Endoscopic transcervical insemination in the bitch. In: CONCANNON, P.W.; ENGLAND, G.; VERSTEGEN, J.; LINDE-FORSBERG, C. Recent Advances in Small Animal Reproduction. New York: IVIS, 2003. Disponível em: http://www.ivis.org. Acesso em: 07 nov. 2013.

WYKES, P.M.; OLSON, P.N. Moléstias do útero. In: BOJRAB, M.J. Mecanismos da moléstia na cirurgia dos pequenos animais. 2.ed. São Paulo: Manole, 1996. Cap. 83, p.665-669.

YANG, J.H.; YANG, Y.J.; KIM, H.S. et al. Intussusception of the uterine horn associated with dystocia in a Thoroughbred broodmare. Korean J. Vet. Res., v.44, p.121-124, 2004. 